\title{
An Interactive E-Learning Tool for Kids in Mauritius
}

\author{
M. S. Sunhaloo, J. Narsoo, and A. Gopaul \\ School of Innovative Technologies and Engineering, \\ University of Technology, Mauritius
}

\author{
sameer.s@utm.intnet.mu; inarsoo@utm.intnet.mu; \\ agopaul002@yahoo.com
}

\begin{abstract}
In this paper, we give an overview of an interactive e-learning tool which we have developed for kids aged from eight to eleven years old in Mauritius. By developing this software, we aim at promoting self learning and developing information and communication technology skills among the youngsters in Mauritius. The e-learning tool developed is based mainly on the science curricula covered at upper primary and lower secondary levels, in the Mauritian schools and colleges respectively. Our software does not intend to render obsolete or replace the existing pedagogical approaches. On the other hand, it will complement the existing teaching and learning methods.
\end{abstract}

Keywords: e-learning, information and communication technology.

\section{Introduction}

Electronic Learning (or e-learning) may be defined as learning using a computer, usually connected to a network. Many researches believe that e-learning is still in its infancy (Kahiigi et al., 2008). Our society can gain tremendously from e-learning. E-learning increases the speed and degree of dissemination of knowledge. It also facilitates the acquisition of knowledge and skills and provides flexible learning opportunities to students. Online learning has a major contribution in the success of distance learning. Nowadays students all over the world are accepting online education, thus compe lling educational institutions to provide online facilities (Erlango et al., 2008; Milani, 2008). The existence of a multitude of online e-learning facilities is bringing changes, which we have been struggling to enforce for the last 25 years, in our curricula. It is acknowledged that e-learning can give better support to the less talented students. It can engage pupils who show poor response to classical classroom learning. On the other hand, for the brilliant students, e-learning can provide them with the opportunity to learn faster. In other words, elearning simply provides a personalised learning experience (Boulton, 2008).

The aim for implementing an interactive online e-learning tool for kids in Mauritius is to promote

Material published as part of this publication, either on-line or in print, is copyrighted by the Informing Science Institute. Permission to make digital or paper copy of part or all of these works for personal or classroom use is granted without fee provided that the copies are not made or distributed for profit or commercial advantage AND that copies 1) bear this notice in full and 2) give the full citation on the first page. It is permissible to abstract these works so long as credit is given. To copy in all other cases or to republish or to post on a server or to redistribute to lists requires specific permission and payment of a fee. Contact Publisher@InformingScience.org to request redistribution permission. e-learning in the country. The tool will increase access to resources in various fields. This will promote self-learning among students and at the same time inculcate information and communication technology (ICT) skills on them. We cannot make Mauritius a cyberis land without developing competent IT skills of the people and this cannot come without a basic knowledge of mathemat- 
ics and science. The main aims and objectives of the interactive e-learning tool are listed be low.

- To provide information on a variety of science topics of importance to the kids.

- To develop a data exchange methodology.

- To make students become independent and allow them to learn at their own pace.

- To enable the students to think and explore a given subject area and increase their knowledge in a more interactive way.

- To promote learning through animation, interactive application and to make learning fun.

- To present learning information to students in appealing and meaningful ways.

The tool will include a forum where different users can interact with each other. The users will be able to search on various topics. There will be a News and Reviews section based on technology, science and culture. Educational games will be provided. A creativity section, for example a painting system, will be included as well.

\section{Education System in Mauritius}

Since Mauritius was a British colony before it became independent in 1968, the education system in Mauritius has largely been modeled on the British system. Post independence, education has always been a priority of the government. To be able to meet the challenges awaiting the country, considerable investment of resources, both human and material, has been put into the education sector. As a result, an impressive progress has been achieved in terms of free, universal, compulsory primary education. Free textbooks are provided to all pupils in primary schools. Free secondary education has also been initiated in Mauritius since 1976 and there is a variety of undergraduate and postgraduate courses offered by the tertiary institutions in Mauritius. Since 1988, the University of Mauritius is providing free full time undergraduate courses. As we can note, the Government of Mauritius has made a substantive effort to provide sufficient funding for education. The government has also been subsidizing significantly private confessional schools, which are administered by the Catholic Church.

In general, children are enrolled in primary schools at the age of six. They are admitted in Standard I and from there, they move automatically to higher standards until they reach Standard IV, where they are categorized via a streaming process. Preparation for the national examination, which is the Certificate of Primary Education, starts as from Standard V. The pupils must study five compuls ory subjects, namely English, French, Mathematics, Science, and History \& Geography. These pupils are also given the opportunity to study Asian languages.

The Certificate of Primary Education results determine the admiss ion of the children into secondary schools. There are two important examinations at the secondary level. After successfully completing five years of study, the students sit for the School Certificate examination. After passing the School Certificate examination, the students sit for the Higher School Certificate examination after studying for two additional years. At colleges, a variety of subjects are taught. From Form 1 up to Form 3, all subjects are compulsory. The science subjects, Economics, Accounting, among others, are optional as from Form 4.

\section{Problem Statement}

Until recently, there has been a cut throat competition at primary level to secure a place in one of the few 'star' secondary schools. As a result, the educational experience of the Mauritian children has been limited mostly to the academic subjects. 
As per the White Paper - Pre Primary \& Secondary Education (n.d.), the present educational system is getting outdated. We do acknowledge that it did help Mauritius to complete its first phase of industrialization. However, as per the White Paper, failure to reform the system may seriously endanger our social harmony.

Statistical analys is indicates that the pass rates at the various important examinations at primary and secondary levels have increased during recent years. However, the figures are biased as they do not consider the dropouts before examinations. Also certain private secondary schools apply some measure of pre-selection before the examinations, thus distorting the true figures.

As per the Global Information Technology Report (2008) on ICT published recently by the World Economic Forum, Mauritius has lost six ranks and is now at the $51^{\text {st }}$ position in the use of ICT for its development. This is a clear indication that, compare to other countries, Mauritius is losing ground in its attempt to develop ICT skills in its population. Clearly, this is not acceptable, as Mauritius is aiming to become a cyber-island. It is a fact that to be science and technology literate is a must nowadays. To be able to cope and contribute in this ever-growing technological world, the new generation must definitely develop excellent competencies and skills in science and technology.

We note that one cannot develop competent ICT skills without having the basic science foundation and particularly mathematics. Thus, prime consideration must be given to the teaching and learning of science. We note that the Mauritius Research Council (MRC) (2004), which is an advisor to the Government of Mauritius, undertook a number of studies in order to assess the status of science and technology in the education sector. The findings of these studies were alarming. Just like it is happening around the world, science subjects are becoming less attractive in the schools and colleges. In fact, fewer than $30 \%$ of the students actually opt for science subjects in the secondary schools.

Since, quality education is a fundamental right for all children irrespective of their socioeconomic class the Government of Mauritius is attempting to provide quality education to all children, despite the fact that our economy is being challenged by the erosion of trade preferences. The government has engaged in this mission with relentless determination and renewed energy. Mauritius is investing massively in ICT and the aim is to provide computer profic iency skills to 400000 trainees over a period of four years with an average of 100000 people each till 2010 .

Educational reform has now become a world wide phenomenon and in Mauritius as well, in the attempt to provide better education, major fundamental reforms are happening in our education sector. We note that in the past there have been several attempts to reform the education system. However, the only outcome of those past reforms was an increase in the number of seats in our schools and colleges. Obviously, to give more children access to schools and colleges is a priority, but it is only a first step towards the achievement a World Class Quality Education for All.

\section{Proposed Action}

\section{Alternative 1}

The first priority is to have an education relevant to the needs of the country bearing in mind that new Information Technology based skills are rapidly replacing the traditional skills all around the world. This means the primary school curriculum must be reviewed so as to give our children a broad-based education that will promote their mental, physical, aesthetic, spiritual and cultural development and at the same time prepare them for the opportunities, responsibilities and experiences of life. 
The new curriculum should meet the development requirements of the country. It must provide the country with an educated and a skilled workforce. It will make our children responsible citizens and equip them with the necessary qualities to face the new challenges of the economy and the trends of the $21^{\text {st }}$ century society.

\section{Alternative 2}

Fundamentally, one of the main objectives of education is to train individuals based on the needs of the society. And the needs of any soc iety are highly influenced by the needs of other societies throughout the world. As a result, the Mauritian educational system must provide education of international standard to its citizens. Nowadays, to be equipped with the ability to access information, to compose, to evaluate, to use information and to communicate with others have become an absolute requirement for trained people. One way to make this necessity easier and more efficient can be located in the integration of the Mauritian educational system into ICT. This integration has two basic elements complementing each other which reflect on the students' needs and this process necessitates both teachers and school principals.

Teachers are required to bring behavioral changes in the students. The teachers are expected to integrate their lessons with ICT in order to train the individuals of an information society. Thus, the teachers should have a sound know ledge of ICT. The teacher should be trained if required.

\section{Alternative 3}

Since the Internet is a craze among youngsters in Mauritius then we should make use of it to provide a way of learning to our students, which can encourage self-learning as well as developing their skills in ICT. It would be interesting to have an online system for kid's age from 8 to 16 years where they can interact with each other and where they are provided with a wide range of resources for their studies.

\section{Analysis of the Different Alternatives}

Alternative 1 seems to be quite an appropriate solution, but it will be a lengthy process to fully implement it. For the second alternative, we can say that providing training is good solution to the problem but it is not cost effective besides the implementation being a long process. The major problem with the second alternative is that we will still be sticking to our traditional way of learning. Despite living in a modern life, students will not be able to develop the ir ICT skills. The third alternative appears to be the best option. The development of an e-learning system for kids will be appropriate. Anyway, if Mauritius aims at becoming a competitive knowledge-based economy, there is an urgent need to foster and actively support the widespread deployment and adoption of e-learning throughout the country, in education, in the home and in industry, especially among youngsters.

\section{An Existing E-Learning Tool for Kids}

E-Learning for Kids is an existing non-profit foundation dedicated to fun and free learning on the Internet for children ages 5-12 with courses in math, science, reading, health and computers. More than 25 e-learning-re lated companies, several associations and 70 individuals are sponsors

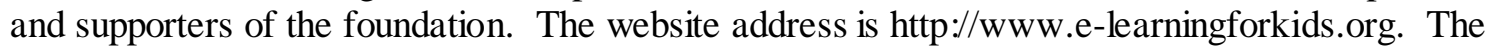
homepage of the website is shown in Figure 1. 


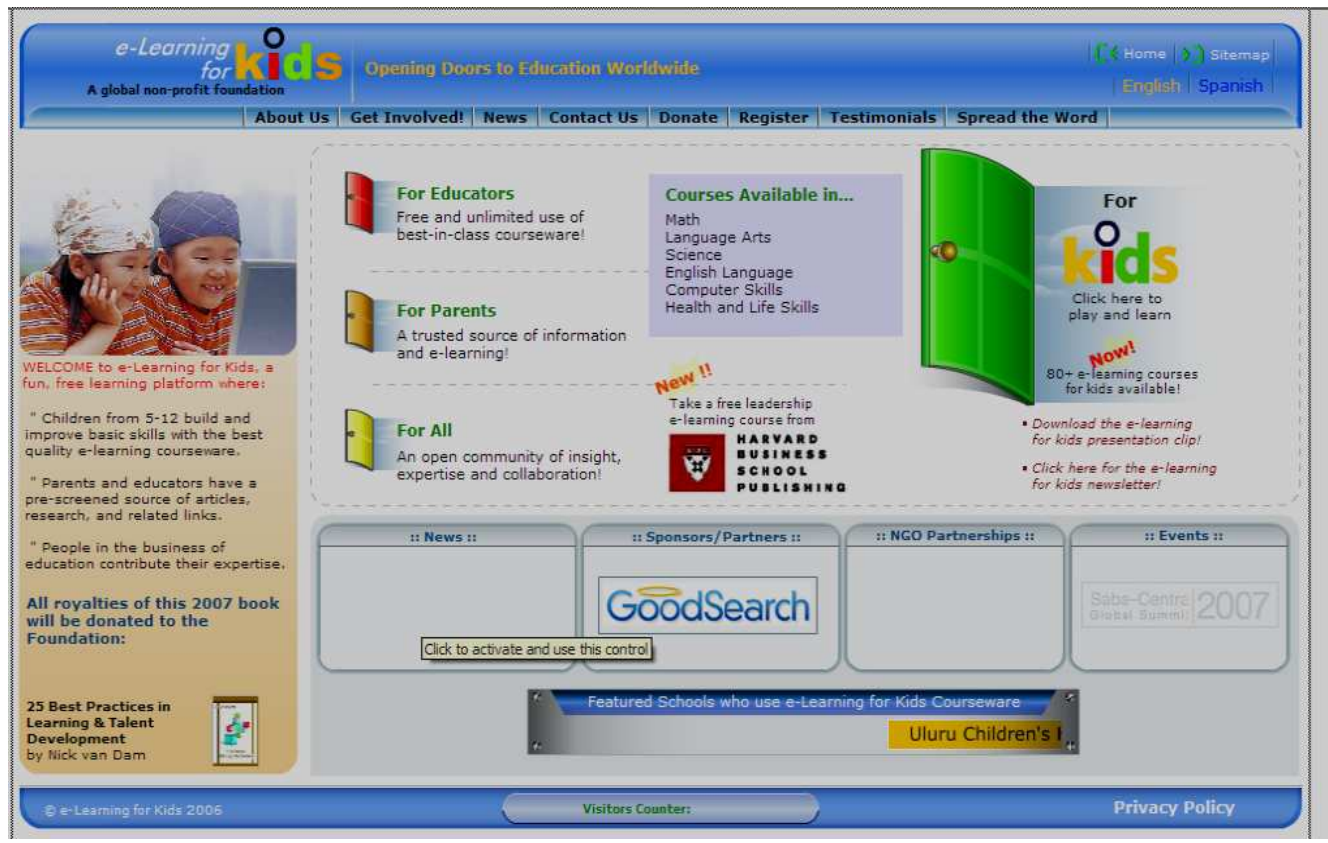

Figure1: Home page of E-learning for Kids (http://www.e-learningforkids.org)

\section{The Proposed E-Learning Tool for Mauritian Kids}

Our e-learning tool will be customized for Mauritian kids. The online e-learning system is a web based application mainly for academic purposes. The website is meant for pupils and students aged from 8 to 16 years old. The system will de liver academic resources especially which are helpful to students in their studies. Similarly it also aims in improving the quality of education as well as encourages self-learning among student and promotes ICT.

In the development of the system, the Rational Unified Process (Kruchten, 2003) has been used as methodology. The system has been developed using several up-to-date technologies.

ASP.NET 2.0 (http://www.asp.net) platform and Visual Basic.Net have been used. JavaScript has been the main client-side scripting language used for validations and the display of user friendly messages to the user. Cascading Style Sheets technology has been used massively which renders the constant display of the design in all the forms. CSS reduces the size of the pages which makes it faster to load than the use of images. XML Technologies have also been used so as to dynamically configure the server from a client host by the administrator. Flash has been used for animations and to provide interaction with the site.

\section{The Application Prototype}

The registration process for the proposed e-learning systems consists of two phases: filling the registration form and attempting a set of 15 questions. Based on the score obtained, the user is allocated a homepage.

The user just has to login using username and password in order to get access to his homepage. We now describe some interesting parts of the system.

\section{Play with Time}

The students are given a fixed amount of time to answer a question. Obviously, a correct answer automatically increases the score by an increment. Based on the final score, the user may be allowed to move to a higher category. 


\section{Fun and Games}

Know your Map: This is an interactive play where the student has to name the district and finally gain marks on the number of correct answers (Figure 2).

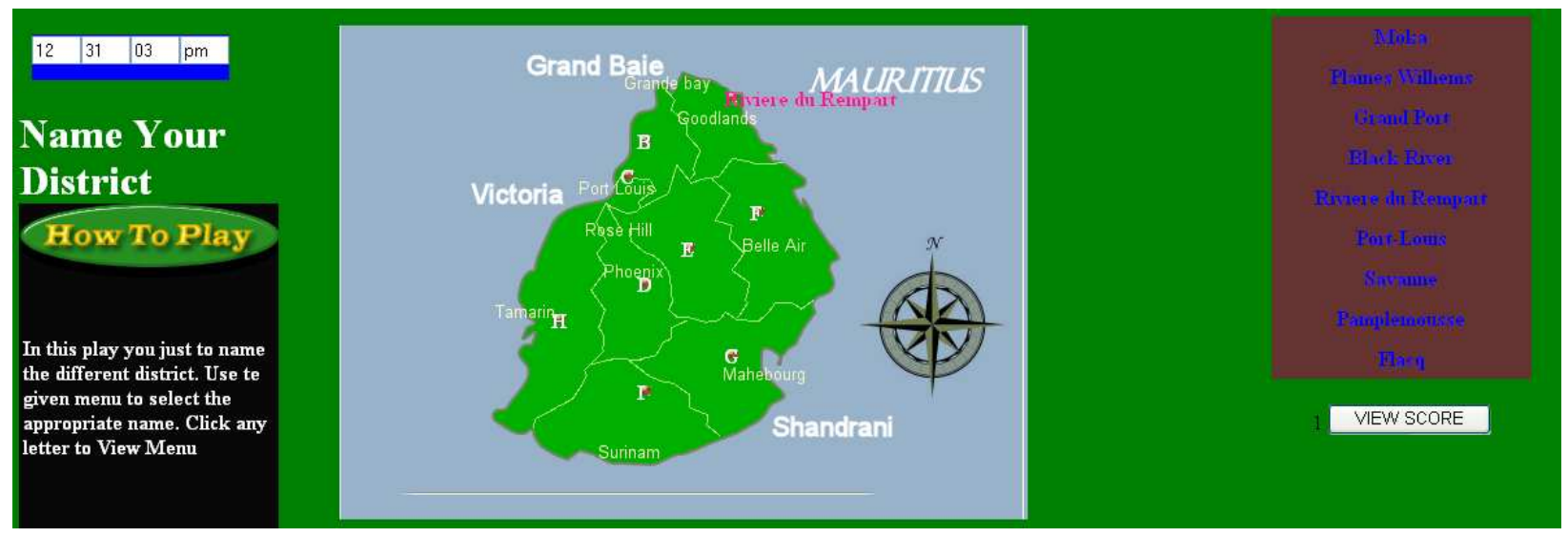

Figure 2: Name Your District.

In Figure 3, a world map is shown. It is a simple activity where the student has just to name the continents
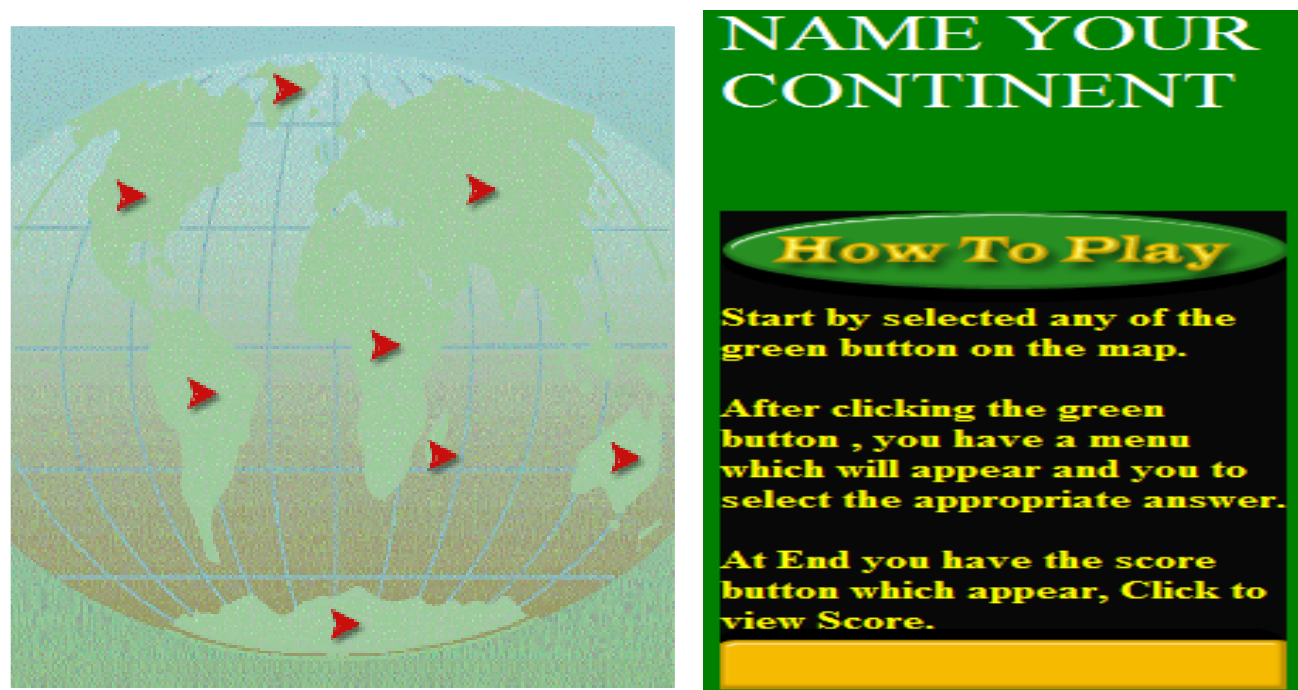

Figure 3: Name Your District.

Figure 4 shows the interface of an interactive drag and drop activity. In this activity the user has to name the planet by simply dragging the appropriate name of the planet and dropping it at the correct location. 


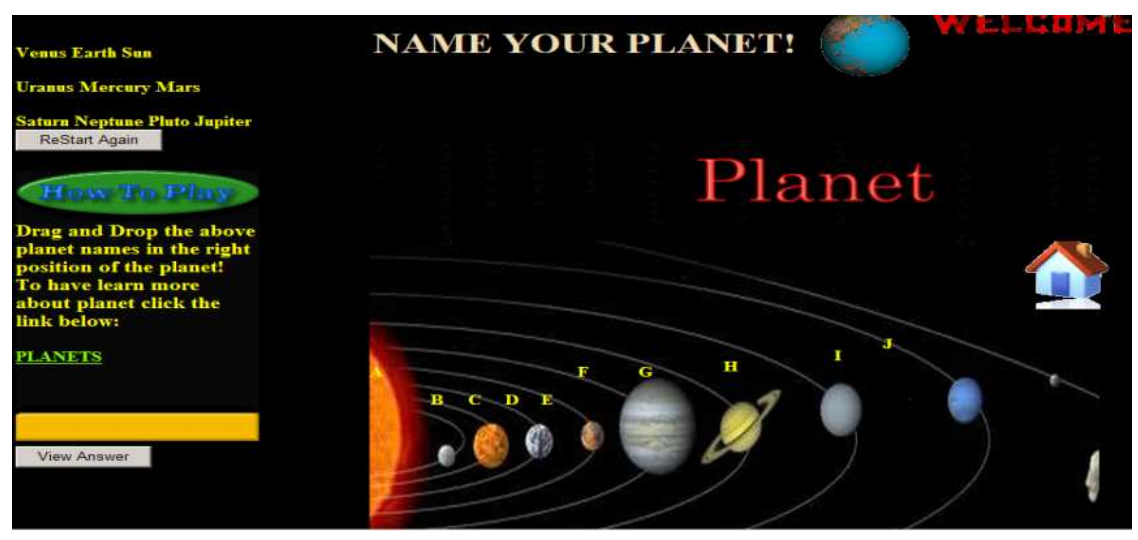

Figure 4: Name the plane ts.

\section{School and Work}

In the school and work section (Figure 5) the user is provided with a menu where s/he can choose a subsection.

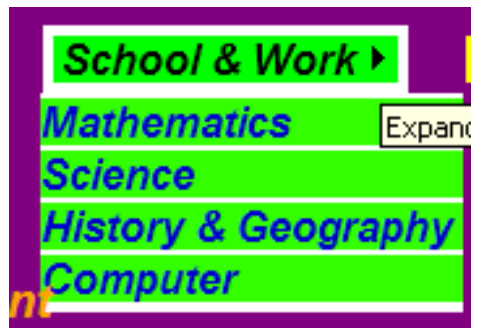

Figure 5: School and work menu.

After choosing a subsection, a list of chapters is provided to the user. The slideshow representation is provided to student based on the chapter selected.

\section{Activity}

In order to train the user academically and improve his or her performance many activities are provided to the user as shown in Figure 6. Through these activities the learner will be able to rate his own performance.

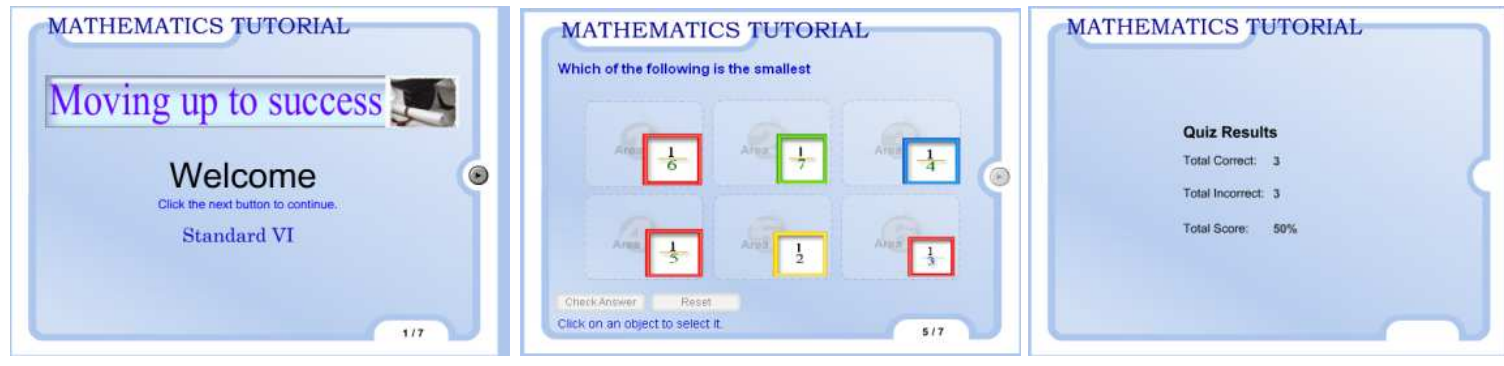

Figure 6: Mathematics Tutorials.

\section{Slideshows}

In order to make learning more interactive slide shows are provided. Figure 7 is a slide show on birds of Mauritius. 

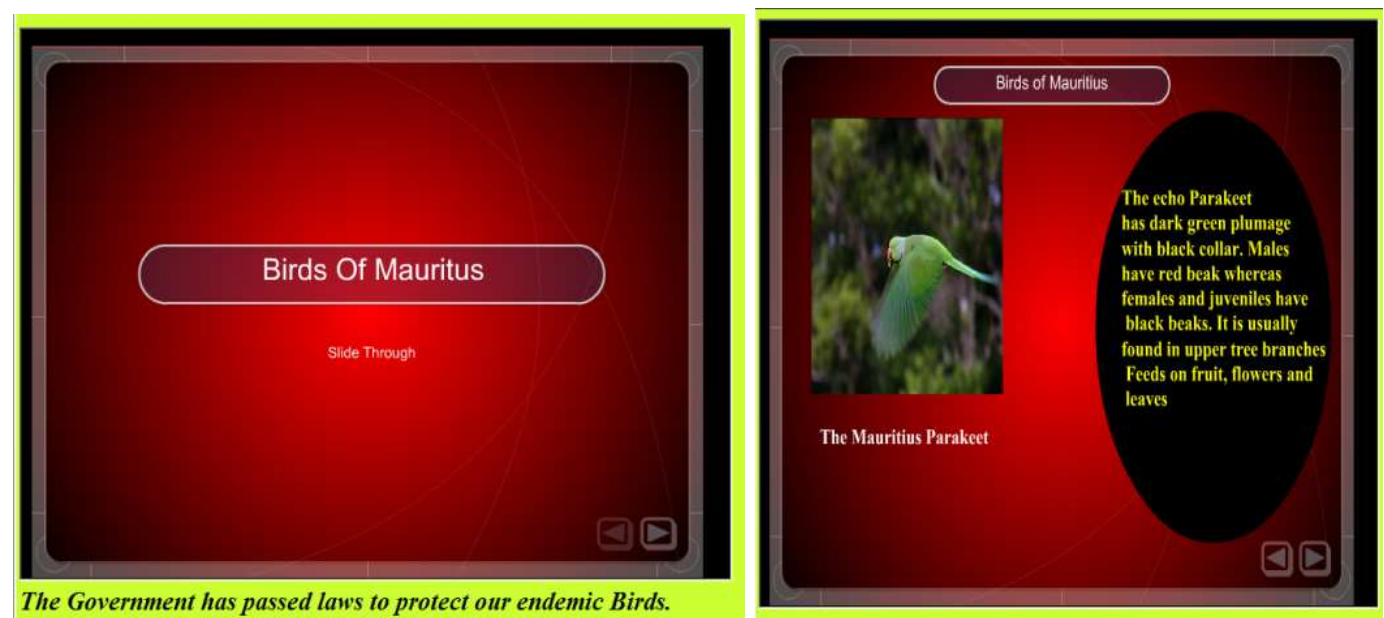

The Government has passed laws to protect our endemic Birds.

Figure 7: Bird Slides how.

\section{Survey Results}

A survey was carried out to investigate about the use of computers among Standard 6 pupils and about the likeness of the developed prototype. Five schools were identified from various parts of the country and from each school 20 pupils were randomly selected.

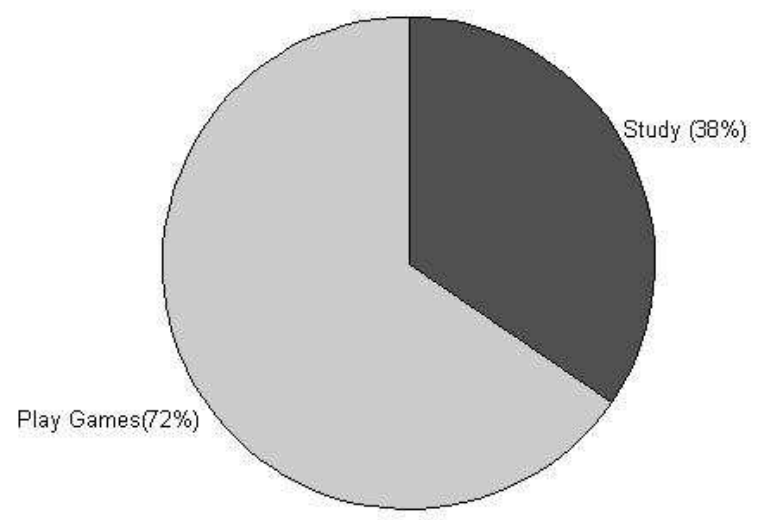

Figure 8: Use of computer.

As shown in Figure 8, most of the pupils use computer to play games. Only $38 \%$ of them use computers to complement their studies. Based on the results depicted in Figure 9, we found that about $50 \%$ of the pupils found the developed prototype is easy to use. 


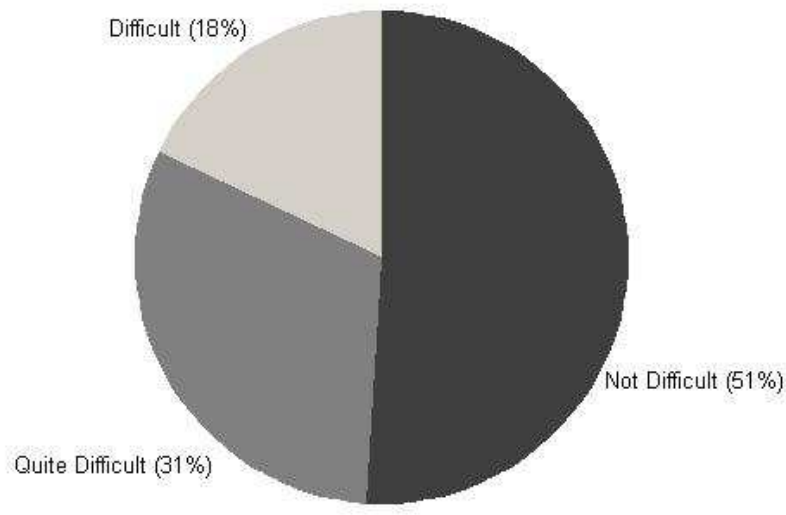

Figure 9: Ease of use of the interactive e-learning tool.

Our survey also revealed that only $20 \%$ of the pupils did not like the software (Figure 10). The different sections (tutorials, quizzes, slide shows, games) of the software were equally appealing to the pupils.

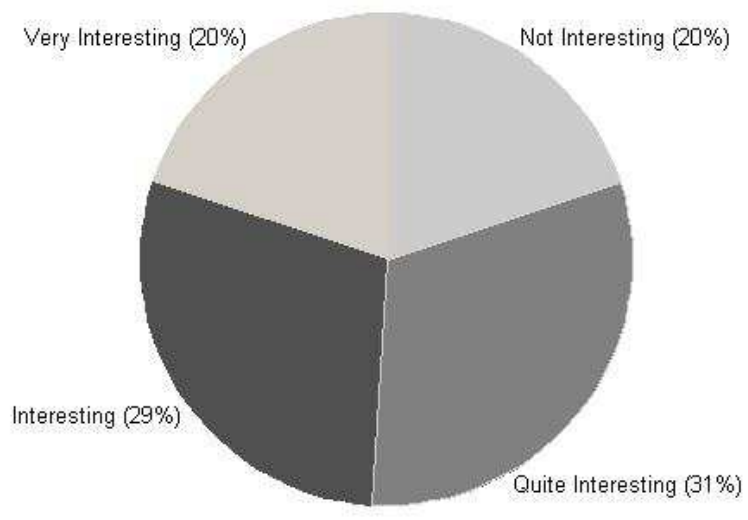

Figure 10: How do the pupils find the interactive e-learning tool.

\section{Conclusion}

We have presented a working prototype of an interactive e-learning tool for Kids. Online education has become popular. The Implementation of an interactive e-learning for kids will enhance education system in Mauritius as well as help in the development of ICT skills in our youngsters. The developed system requires some fine tuning which we intend to complete in the near future. 


\section{References}

Boulton, H. (2008). Managing e-learning: What are the real implications for schools? Electronic Journal of e-Learning, 6(1), 11-18.

Bhuwanee, T. (2001). Concept paper: Reg ional Workshop on Secondary Education.

Elango, R., Gudep, V. K., \& Selvam M. (2008). Quality of e-learning: An analysis based on e-learners' perception of e-learning. Electronic Journal of e-Learning, 6(1).

The Global Information Technology Report 2007-2008. (2008). World Economic Forum.

Kahiigi, E. K., Ekengerg, L., Hansson, H., Tusuvira, F. F. \& Danielson, M. (2008). Exploring the elearning state of art. Electronic Journal of e-Learning, 6(2).

Kruchten, P. (2003). The rational unified process: An introduction. Addison-Wesley.

Mauritius Research Council. (2004). Science Education: An action plan.

Milani, M. (2008). Cultural impact on online education quality perception. Electronic Journal of eLearning, 6(2), 149-160.

White Paper - Pre Primary \& Secondary Education - Mauritius. (n.d.) Min istry of Education and Scientific Research, Mauritius (http://www.ilo.org/public/english/employment/skills/hrdr/init/mau 1.htm)

\section{Biographies}

M.S. Sunhaloo is a Senior Lecturer at the University of Technology Mauritius.

J. Narsoo is a Lecturer at the University of Technology Mauritius.

A. Gopaul is a postgraduate student at the University of Technology Mauritius. 